Please do not remove this page

RMIT

UNIVERSITY

\title{
Cavity backed hi-lo stacked patch antennas
}

Elmezughi, Abdurrezagh; Rowe, Wayne; Waterhouse, Peter

https://researchrepository.rmit.edu.au/esploro/outputs/9921863944201341/filesAndLinks?institution=61RMIT_INST\&index=null

Elmezughi, A., Rowe, W., \& Waterhouse, P. (2008). Cavity backed hi-lo stacked patch antennas. IEEE International AP-S Symposium, 1-4. https://doi.org/10.1109/APS.2008.4620007

Published Version: https://doi.org/10.1109/APS.2008.4620007

Repository homepage: https://researchrepository.rmit.edu.au

(c) 2008 IEEE. Personal use of this material is permitted. However, permission to reprint/republish this material for advertising or promotional purposes or for creating new collective works for resale or redistribution to servers or lists, or to reuse any copyrighted component of this work in other works must be obtained from the IEEE.

Downloaded On 2023/04/26 23:57:17 +1000 


\title{
Cavity Backed Hi-lo Stacked Patch Antennas
}

\author{
A. S. Elmezughi ${ }^{(1)}$, W. S. T. Rowe ${ }^{(1)}$ and R. B. Waterhouse*(2) \\ ${ }^{(1)}$ RMIT University, Melbourne, VIC 3001, Australia \\ ${ }^{\text {(2) }}$ Pharad, Glen Burnie, MD 21061, USA \\ Contact: wayne.rowe@rmit.edu.au
}

\section{Introduction}

At previous symposia we have introduced edge-fed cavity backed patch antennas as an alternative to a conventional edge-fed configuration that overcomes several of the inherent issues associated with this architecture [1,2]. We have shown both theoretically and experimentally that this dielectric filled cavity backed radiator has significantly higher efficiency and less pattern scalping than a traditional edge-fed patch for two reasons: (i) the cavity reduces the amount of surface wave propagation; and (ii) the thin substrate layer used to etch the feed network allows for a thinner track width to realize a $50 \Omega$ characteristic impedance, and therefore reduces spurious radiation from the feed network. The new cavity backed edgefed radiator shows a $3 \mathrm{~dB}$ improvement in the gain, and reduces the pattern undulation by $10 \mathrm{~dB}$. The attributes of this architecture are particularly suited to large planar arrays, which is a prevalent application of edge-fed microstrip patches.

A variation of this cavity backed procedure [2] can be applied to radiators that can be directly integrated on Monolithic Microwave Integrated Circuit (MMIC) and Opto-Electronic Integrated Circuit (OEIC) materials [3]. The new configuration potentially overcomes the trade-offs associated with trying to develop patch-based radiators on very thin, high dielectric constant material. In this investigation the cavity was filled with air to simplify the manufacturing procedure of the radiator. The cavity essentially becomes part of the package used to house the antenna and MMIC/OEIC. The increase in depth between the patch conductor and the ground-plane for the cavity backed case resulted in an impedance bandwidth that was more than twice that obtained for an equivalent conventional edge-fed patch. The cavity backed version also has approximately $2 \mathrm{~dB}$ greater gain. Although these are very promising results, the achievable bandwidth is still quite low.

The hi-lo stacked patch antenna element [4] is a proven technique to enhance the bandwidth of printed antennas incorporated into MMIC/OEIC technology and packaging. The hi-lo stacked patch antenna consists of a driven edge-fed patch element on high permittivity material that is parasitically coupled second patch separated vertically by a low dielectric constant laminate. This combination of high and low dielectric constant microwave laminates produces an efficient broadband printed antenna. In this paper we investigate applying the hi-lo substrate architecture to the edge-fed cavity backed patches on high permittivity material in [2] with a view to significantly expanding the usable bandwidth. 


\section{Creation of the Hi-lo Structure}

Figure 1 shows a schematic of an integratable edge-fed cavity backed patch similar to the one developed in [2]. This was used as the basis for the investigation into the bandwidth enhancement will the application of the hi-lo technique. The driven patch and microstrip feed line are etched on a $0.635 \mathrm{~mm}$ layer of Rogers RT/Duroid 6010.2 which is mounted on top of an aluminum block with an air filled cavity of $10 \mathrm{~mm} \times 10 \mathrm{~mm} \times 3 \mathrm{~mm}$ located below the patch. The $50 \Omega$ feed line is $0.6 \mathrm{~mm}$ wide. A small aluminum flange was constructed to mount an SMA connector, and the center pin of this adaptor was soldered to the microstrip transmission line. Epoxy and Nylon screws were used to attach the high permittivity substrate to the aluminum package. The dimensions are the same as those in [2], with the exception that the inset feed has now been removed. The patch is now fed directly at its edge.

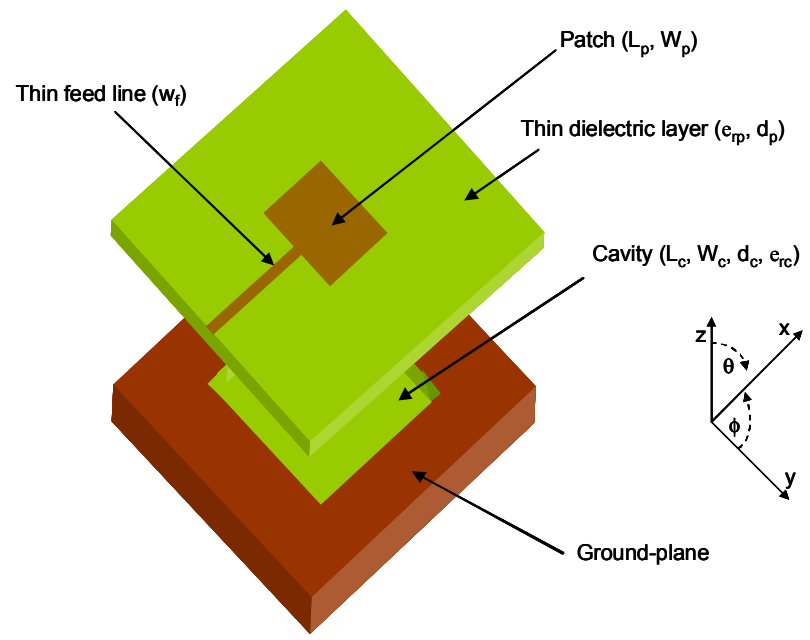

Figure 1. Schematic of the edge-fed cavity backed patch antenna using high permittivity material

$\left(\right.$ Parameters $-d_{p}=0.635 \mathrm{~mm}, \varepsilon_{\mathrm{rp}}=10.2, \tan \delta_{\mathrm{f}}=0.0023, \mathrm{w}_{\mathrm{f}}=0.6 \mathrm{~mm}, \mathrm{~L}_{\mathrm{c}}=11 \mathrm{~mm}$, $\left.W_{c}=11 \mathrm{~mm}, d_{c}=0.03 \mathrm{~mm}, L_{p}=10 \mathrm{~mm}, W_{p}=10 \mathrm{~mm}\right)$

The hi-lo configuration was formed by stacking a square parasitic patch on top of this structure, separated by a foam dielectric layer. The patch is etched on a thin Rogers RT/Duroid 5880 laminate which is placed on top of the foam. The parameters of this upper section of the hi-lo stacked patch were optimized via simulation using Ansoft HFSS version 10.

\section{Characterization of the Hi-lo Cavity Backed Patch Antenna}

The hi-lo cavity backed patch antenna was fabricated, and the performance of this radiator was experimentally characterized. The measured return loss is given in Figure 2. The antenna achieves an impedance bandwidth (defined as $>10 \mathrm{~dB}$ return loss) of $26 \%$. The HFSS simulation results predicted a bandwidth of $24.6 \%$ with a shift to a slightly lower frequency range. This shift was attributed 
to a slight variation in the foam thickness between the upper and lower patch elements of the hi-lo cavity backed patch. For comparison, a hi-lo stacked patch without cavity backing was also designed in HFSS using the same feed and driven patch arrangement. The non-cavity backed hi-lo could only achieve a $16 \%$ impedance bandwidth, highlighting the benefit of creating a small hollow region in the packaging of an integrated MMIC/OEIC antenna.

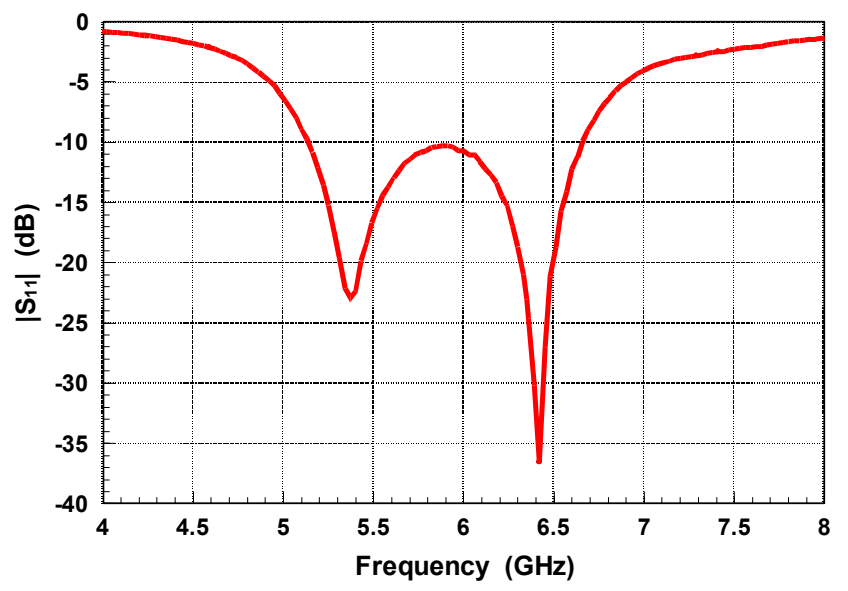

Figure 2. Measured return loss of the developed hi-lo cavity backed patch

The radiation performance of the hi-lo cavity backed antenna was measured at a frequency of $6 \mathrm{GHz}$, which is approximately the centre of the impedance bandwidth. The co-polar and cross-polar E- and H-plane radiation patterns are portrayed in Figure 3. The radiated fields show minimal pattern undulation and low cross-polarization levels, which are more than $20 \mathrm{~dB}$ below co-polar broadside level in both planes.

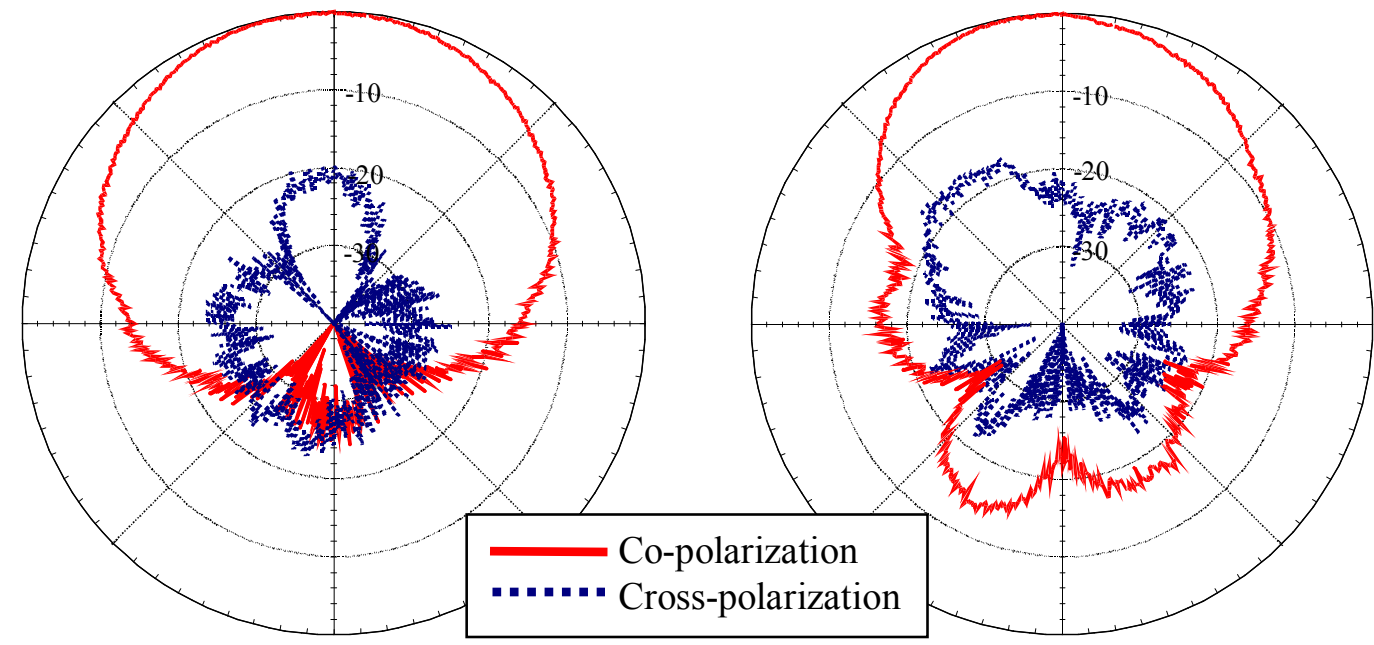

(a)

(b)

Figure 3. Measured radiation patterns of the hi-lo cavity backed patch antenna at 6 GHz: (a) H-plane (b) E-plane 
The gain of the antenna was measured using the gain substitution method with a frequency step size of $0.5 \mathrm{GHz}$ (limited by the gain data available from the standard gain horn). The results are plotted in Figure 4. The measured gain cycles around $6 \mathrm{dBi}$ in the middle of the impedance bandwidth, and diminishes at the upper and lower bandwidth edges. The simulated radiation efficiency of this antenna is $96 \%$.

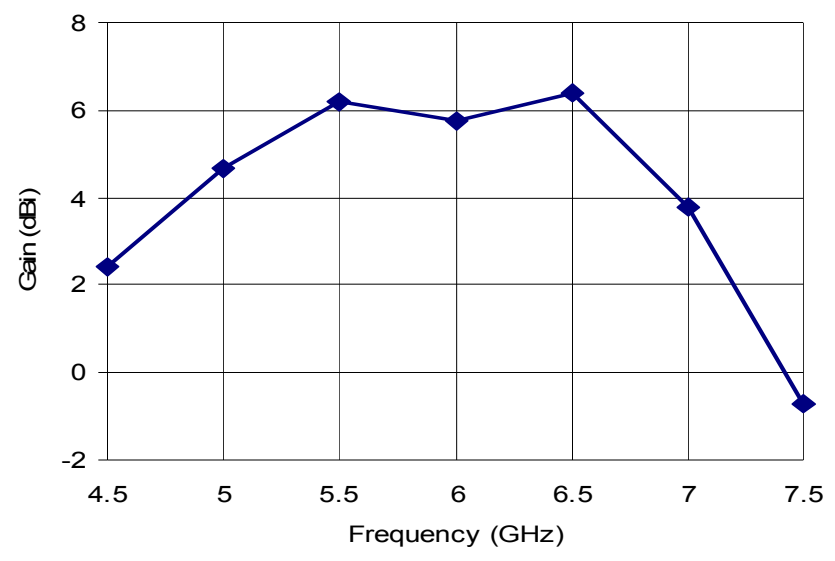

Figure 4. Measured antenna gain of the hi-lo cavity backed patch

The results presented in this paper highlight the inherent advantages in terms of wide bandwidth and efficiency for this novel patch antenna structure. As previously mentioned, this hi-lo cavity backed antenna application is a perfect option for antennas integrated with MMIC and OEIC technology. The cavity can be easily incorporated into the package of the antenna and integrated circuit. The hi-lo substrate structure has been shown to increase the bandwidth to $26 \%$ from the $3 \%$ of a single element edge-fed cavity backed patch, while maintaining pattern integrity and radiation efficiency.

\section{References}

[1] W. S. T. Rowe and R. B. Waterhouse, "Investigation of edge-fed cavity backed patches", Proc. IEEE. Ant. \& Prop. Symp., Albuquerque, NM, pp. 3967 - 3970, July 2006.

[2] A. S. Elmezughi, W. S. T. Rowe and R. B. Waterhouse, "Further investigations into edge-fed cavity backed patches", Proc. IEEE. Ant. \& Prop. Symp., Honolulu, HI, pp. 920 - 923, June 2007.

[3] W. S. T. Rowe and R. B. Waterhouse, "Efficient wideband printed antennas on Lithium Niobate for OEICs", IEEE Trans. Ant. \& Prop., vol. 51, pp. 1413 - 1415, June 2003.

[4] R. B. Waterhouse, "Stacked patches using high and low dielectric constant material combination," IEEE Trans. Antennas Propag., vol. 47, pp. 1767$1771,1999$. 